\title{
Flora da Usina São José, Igarassu, Pernambuco: Sapindaceae
}

\author{
Flora of the Usina São José, Igarassu, Pernambuco: Sapindaceae
}

\author{
Luiz de Aquino Pereira ${ }^{1,4}$, Bruno Sampaio Amorim ${ }^{1}$, Marccus Alves ${ }^{1}$, Genise Vieira Somner ${ }^{2}$ \\ \& Maria Regina de Vasconcellos Barbosa ${ }^{3}$
}

\begin{abstract}
Resumo
Sapindaceae é uma família predominantemente tropical com aproximadamente 1.900 espécies em todo o mundo. No Brasil ocorrem 418 espécies, que têm como principais centros de diversidade a Floresta Amazônica e a Floresta Atlântica. A Usina São José, localizada ao norte do estado de Pernambuco, é formada basicamente por fragmentos de Floresta Estacional Semidecidual. Nela foram registrados sete gêneros e 14 espécies de Sapindaceae. Cupania o mais rico com quatro espécies, seguido de Paullina com três espécies, Serjania e Talisia ambos com duas espéices e Allophylus, Cardiospermum e Matayba todos com uma espécie. Este tratamento apresenta chave de identificação, descrições, ilustrações e comentários taxonômicos das espécies. Palavras-chave: florística, taxonomia, Floresta Atlântica.
\end{abstract}

\begin{abstract}
Sapindaceae is predominantly a tropical family with about 1,900 species worldwide. In Brazil, there are 418 species recorded so far, whose main centers of diversity are the Amazon and Atlantic Forests. The Usina São José, located north of the state of Pernambuco, is basically formed by semideciduous forest fragments. It was recorded seven genera and 14 species of Sapindaceae, Cupania is the richest one with 4 species, followed by Paullina with three species, Serjania and Talisia both with two species and Allophylus, Cardiospermum and Matayba all with one species each. This taxonomic treatment provides identification key, descriptions, illustrations and ecological and taxonomic comment of the species.
\end{abstract}

Key words: floristic, taxonomy, Atlantic Forest.

\section{Introdução}

Sapindaceae compreende 141 gêneros e 1.900 espécies distribuídas predominantemente em regiões tropicais, com poucos táxons alcançando as zonas temperadas (Acevedo-Rodríguez et al. 2011). No Brasil ocorre em diferentes fitofisionomias, mas tem como principais centros de diversidade a Floresta Amazônica e a Floresta Atlântica (Acevedo-Rodríguez 1993). Atualmente são reconhecidos 28 gêneros e 418 espécies brasileiras, das quais 126 ocorrem na Mata Atlântica nordestina (BFG 2015).

A família é formada por árvores, arbustos ou trepadeiras, e é caracterizada morfologicamente por apresentar folhas compostas de filotaxia alterna, inflorescência constituída de tirsos, as trepadeiras apresentam um par de gavinhas na base da raque, com flores aparentemente hermafroditas, porém funcionalmente unissexuadas. As flores são 4 ou 5-meras e o disco nectarífero geralmente extra-estaminal de formas distintas. Os frutos são deiscentes ou indeiscentes, variando de bagas, cápsulas a esquizocárpicos com mericarpos alados ou cocos drupáceos.

As espécies de Sapindaceae são importantes constituintes do dossel da vegetação nas florestas tropicais, sendo citadas entre as famílias mais ricas em áreas de Floresta Atlântica (Hora \& Soares

\footnotetext{
${ }^{1}$ Universidade Federal de Pernambuco, Depto. Botânica, Av. Prof. Moraes Rêgo s/n, 50670-901, Recife, PE, Brasil.

${ }^{2}$ Universidade Federal Rural do Rio de Janeiro, Depto. Botânica, Rod. BR 465, Km 7 s/n, 23851-970, Seropédica, RJ, Brasil.

${ }^{3}$ Universidade Federal da Paraíba, Depto. Sistemática e Ecologia, Cidade Universitária s/n, 58051-900, João Pessoa, PB, Brasil.

${ }^{4}$ Autor para correspondência: luizdeaquinopereira@gmail.com
} 
2002). Estas desempenham importante papel na dinâmica ambiental formando verdadeiros "corredores biológicos" no dossel das florestas, permitindo o deslocamento de animais arborícolas, além de servirem como fonte de recursos nutricionais para espécies animais características da Floresta Atlântica (Aschoff 2012). Mais de 50 espécies de Sapindaceae são utilizadas pelo homem com finalidades econômicas, na construção civil, na indústria madeireira, alimentícia e farmacêutica (Guarim-Neto et al. 2000).

Estudos florísticos com a família Sapindaceae na Floresta Atlântica do sudeste e sul do Brasil estão disponíveus em floras regionais (Reitz 1980; Somner et al. 2009). Na Floresta Atlântica do Nordeste do Brasil, os estudos limitam-se a áreas de florestas montanas nos estados de Pernambuco e da Bahia (Oliveira 1998; Perdiz 2011), bem como em áreas de Floresta Estacional Semidecidual na porção mais oriental da Floresta Atlântica (Pereira 2014). Dessa forma este trabalho tem como objetivo realizar o tratamento taxonômico da família Sapindaceae na Usina São José (USJ) visando ampliar o conhecimento deste grupo na Floresta Atlântica nordestina. Este trabalho dá continuidade a série de monografias de famílias botânicas ocorrentes nos remanescentes florestais da Usina São José, no norte do estado de Pernambuco.

\section{Material e Métodos}

A Usina São José (USJ) localiza-se na Zona da Mata Norte, a $28 \mathrm{~km}$ de Recife, no município de Igarassu - Pernambuco (7०40'21,25"-7055'50,9'S e $34^{\circ} 54^{\prime} 14,25^{\prime \prime}-35^{\circ} 5^{\prime} 21,0^{\prime \prime} \mathrm{W}$ ) (Trindade et al. 2008). Possui uma área total de $280 \mathrm{~km}^{2}$ e cerca de 100 fragmentos florestais com diferentes áreas. Para a classificação dos habitats nos fragmentos estudados, adotou-se Silva et al. (2008). As coletas foram realizadas durante o período de 2008-2012 e concentraram-se em seis fragmentos selecionados com área entre 30-400 m² (Araujo \& Alves 2010).

As amostras botânicas foram submetidas às técnicas usuais em herborização (Mori et al. 1985) e depositadas nos herbários JPB, IPA, PEUFR e UFP, com duplicatas distribuídas nos herbários NY, RB e RBR. Adicionalmente, foram consultadas e incluídas informações obtidas a partir de análises das coleções depositadas nos herbários ALCB, ASE, BOTU, CEPEC, EAN, HRCB, IAC, IPA, JPB, MAC, PEUFR, R, RB, RBR, SP, SPF, SPSF, UEC, UFP, UFRN (acrônimos segundo Thiers, continuamente atualizado) e HST (Herbário
Sérgio Tavares da Universidade Federal Rural de Pernambuco).

As identificações foram realizadas com o auxílio de bibliografia especializada (AcevedoRodriguez 1993; Acevedo-Rodriguez 2003; Ferrucci 1991; Ferrucci 2000; Radlkofer 18921900; Somner 2001; Somner et al. 2009). A caracterização morfológica foi baseada em Font Quer (1953), Harris \& Harris (2001) e Radford et al. (1974). A descrição a família foi baseada apenas nas espécies estudadas na USJ e para a classificação dos tipos de caules presentes em Sapindaceae foi utilizado Tamaio \& Angyalossy (2009).

A monografia elaborada segue o modelo de outras previamente publicadas para a área de estudo (Alves-Araújo \& Alves 2010; Buril \& Alves 2011; Gomes-Costa \& Alves 2012). As descricções de família e gênero estão baseadas nas espécies ocorrentes na área de estudo. Os nomes das espécies e dos autores, bem como dados de distribuição geográfica estão de acordo com $\mathrm{BFG}$ (2015).

\section{Resultados e Discussão}

Na área da USJ, Sapindaceae está representada por sete gêneros e 14 espécies. O gênero com maior riqueza de espécies é Cupania com quatro espécies, seguido de Paullinia com três, Serjania e Talisia ambos com duas espécies e Allophylus, Cardiospermum e Matayba com uma espécie cada. O presente tratamento taxonômico acrescentou três espécies ao checklist de Melo et al. (2011). Apesar de não ter sido encontrada na área de estudo Paullinia elegans Cambess., provavelmente, ocorra nos fragmentos florestais da USJ, visto que há registros de sua ocorrência em áreas próximas. Esta pode ser diferenciada das demais espécies de Paullinia deste tratamento por apresentar folhas e frutos desprovidos de alas.

A maior parte das espécies tratadas é de ampla distribuição no território brasileiro. Embora ocorram em diferentes regiões fitogeográficas, sete espécies são consideradas endêmicas do Brasil: Allophylus puberulus (Turcz.) Radlk., Cupania impressinervia Acev.-Rodr., Cupania ludowigii Somner \& Ferrucci, Cupania oblongifolia Mart., Cupania racemosa (Vell.) Radlk., Paullinia racemosa Wawra e Serjania salzmanniana Schltdl. $\mathrm{Na}$ USJ as espécies ocorrem preferencialmente na borda dos remanescentes florestais com exceção de Talisia retusa R.S. Cowan, que só foi coletada no interior dos fragmentos. 


\section{Tratamento Taxonômico \\ Sapindaceae Juss.}

Árvores, arbustos ou trepadeiras herbáceas ou lenhosas; monóicas, latescentes ou não; caule em seção transversal com apenas um único cilindro vascular ou com um cilindro vascular central e vários cilindros vasculares periféricos; com ou sem estípulas. Folhas alternas, compostas pinadas ou ternadas; folíolos com margem geralmente inteira, denteada ou denteado-serreada, com ou sem domácias na face abaxial. Inflorescências tirsos espiciformes, racemiformes ou paniculiformes, axilares ou terminais, nas trepadeiras com um par de gavinhas na base da raque. Flores unissexuadas, tetrâmeras ou pentâmeras, actinomorfas ou zigomorfas, as estaminadas geralmente com pistilódio circundado pelos estames, as pistiladas com estaminódios ao redor do gineceu; cálice dialissépalo ou gamossépalo; corola dialipétala, pétalas apendiculadas; nectários extra-estaminais, em forma de disco anelar, hemidisco ou 4 lobos nectaríferos; estames 8 , livres ou soldados na base, anteras dorsifixas, bitecas, rimosas; gineceu gamocarpelar, geralmente (2)3-carpelar, (1-2)3-locular, 1 óvulo anátropo por lóculo, placentação geralmente axial, estilete filiforme, estigma bífido, trífido ou inteiro. Fruto cápsula loculicida ou septífraga, baga, esquizocarpo com mericarpos alados, cocos drupáceos; sementes com ou sem excrescência.

\section{Chave para identificação das espécies de Sapindaceae da Usina São José}

1. Árvores ou arbustos, folhas 3-folioladas ou pinadas, neste caso com apículo terminal no ápice da raque, sem estípulas.

2. Folhas 3-folioladas s; flores tetrâmeras, zigomorfas; nectário unilateral, em forma de hemidisco; fruto esquizocárpico, cocos drupáceos...... 1. Allophylus puberulus

2'. Folhas pinadas; flores pentâmeras, actinomorfas; nectário em forma de disco anelar; fruto cápsula loculicida ou baga.

3. Folíolos ferrugíneo-tomentosos na face abaxial, nervuras impressas na face adaxial, venação craspedódroma

3'. Folíolos glabros na face abaxial, nervuras não-impressas na face adaxial, venação broquidódroma.

4. Folíolos com domácias na axila das nervuras secundárias; pétalas obovadas, unguiculadas; fruto cápsula loculicida.

5. Cálice curtamente gamossépalo; cápsula com epicarpo verrucoso

7. Matayba guianensis

5'. Cálice dialissépalo; cápsula com epicarpo estriado ou lenticelado.

6. Pétalas com apêndices falciformes inseridos na região mediana; cápsula bivalvar. 4. Cupania ludowigii

6'. Pétalas com fenda mediana formando apêndices marginais; cápsula trivalvar. 7. Ápice dos folíolos obtuso, emarginado; cápsula globosa, com epicarpo lenticelado 5. Cupania oblongifolia

7'. Ápice dos folíolos agudo, acuminado; cápsula trígona, com epicarpo estriado

6. Cupania racemosa

4'. Folíolos sem domácias; pétalas elípticas a oblongas; fruto baga.

8. Folíolos com ápice mucronado, retuso ou emarginado; tirso paniculiforme

8'. Folíolos com ápice acuminado; tirso racemiforme 13. Talisia esculenta

1'. Trepadeiras, folhas biternadas ou imparipinadas, apículo terminal ausente, com estípulas.

9. Folhas com raque alada

10. Folhas biternadas; fruto esquisocárpico com mericarpos alados

11. Serjania paucidentata

10'. Folhas imparipinadas; fruto cápsula septífraga.

11. Folhas 5-folioladas; caule em secção transversal formado por um cilindro vascular central maior e três cilindros vasculares periféricos menores; fruto piriforme, não-alado 
11'. Folhas 9-11-folioladas; caule em secção transversal formado por um cilindro vascular; fruto obovoide, 3-alado.

8. Paullinia micrantha

9'. Folhas com raque não-alada.

12. Tirsos com três ramificações; cápsula inflada

2. Cardiospermum halicacabum

12'. Tirsos com mais de três ramificações; cápsula não inflada.

13. Folhas biternadas (9-folioladas); fruto esquizocárpico

12. Sejania salzmanniana

13'. Folhas imparipinadas (5-folioladas); fruto capsula septifraga......

10. Paullinia racemosa

1. Allophylus puberulus (Turcz.) Radlk., Nat. Pflanzenfam. Engler \& Prantl 3. Abt. 5: 312. 1895; Schmidelia puberula Cambess. in St.-Hil., Fl. Bras. Merid. 1:382. 1825.

Fig. 1a

Arbustos a árvores até $10 \mathrm{~m}$ alt., nãolatescentes, ramos floríferos lenticelados e pilosos quando jovens. Folhas imparipinadas 3 -folioladas; pecíolo 1-4,5 cm compr., canaliculado; folíolos 1,5$15 \times 0,5-5,5 \mathrm{~cm}$, elípticos a obovados; ápice agudo a obtuso; margem denteado-serreada; base aguda a atenuada; face adaxial glabra, tricomas na nervura central; face abaxial pubérula, domácias na axila das nervuras secundárias, venação craspedódroma. Tirsos 1,5-5 cm compr., espiciformes, axilares. Flores 2,5-4 mm compr., tetrâmeras, zigomorfas, cálice dialissépalo, sépalas 1-2 mm compr., pétalas 1,5-2 mm compr., obovadas, unguiculadas, apêndice formado por um tufo de tricomas na face adaxial da pétala, vilosas; nectário unilateral em forma de hemidisco, 4-lobado; estames 1,5-3 mm compr., filetes vilosos, pistilódio glabro; estaminódios 1 $\mathrm{mm}$ compr., gineceu $2 \mathrm{~mm}$ compr., estigma bífido ou trífido. Fruto esquizocárpico, $0,4-0,8 \times 0,4-0,6$ $\mathrm{cm}$, globoide a elipsoide, cocos drupáceos, glabros. Semente $0,4-0,6 \times 0,2-0,3 \mathrm{~cm}$, elipsoide.

Material examinado: Mata de Macacos, 23.XII.2011, fr., B.S. Amorim et al. 1331, (UFP); Mata de Pezinho, 20.VI.2008, fl., L.M. Nascimento et al. 651 (UFP); 01.XII.2011, fr., B.S. Amorim et al. 1308 (UFP); Mata de Piedade, 09.VIII.2007, fr., A. Alves-Araújo et al. 503 (UFP); 12.VII.2008, bt., L.M. Nascimento et al. 763 (UFP); 8.IX.2008, fr., T.N.F. Guerra et al. 88 (UFP); 10.I.2008, bt., A. Alves-Araújo et al. 804 (UFP).

Espécie endêmica do Brasil, referida para os estados do Pará, Tocantins, Alagoas, Bahia, Ceará, Maranhão, Paraíba, Pernambuco, Rio Grande do Norte, Sergipe, Espírito Santo, Minas Gerais, Rio de Janeiro, São Paulo e Paraná (BFG 2015). Na USJ é comum na borda dos fragmentos. Pode ser diferenciada das demais espécies arbóreas por apresentar folhas 3-folioladas e flores zigomorfas. Amostras dessa espécie estavam erroneamente identificadas, nos herbários consultados, como $A$. edulis e A. laevigatus, que foi sinonimizada em $A$. puberulus por Coelho (2014). A partir de dados da morfologia dos folíolos e dos nectários pôdese confirmar sua real identidade. Popularmente é conhecida como fruta-de-pombo.

2. Cardiospermum halicacabum L., Sp. pl.: 366 . 1753.

Fig. 1b

Trepadeiras herbáceas, não-latescentes, caule 5-6 sulcado, em secção transversal com um cilindro vascular, pubérulo a glabro; estípulas triangulares, caducas. Folhas biternadas 9-folioladas; pecíolo 1-4 cm compr., canaliculado, raque não alada, apículo terminal ausente; folíolos 1-4,5 × 0,5-4,5 cm, sem domácias, ovados a oblongos; ápice acuminado a arredondado; margem ciliada, profundamente denteada; base cuneada; face adaxial e abaxial pubérulas a glabras; venação craspedódroma. Tirsos espiciformes, axilares, com três ramificações. Flores 2,5-4 mm compr., tetrâmeras, zigomorfas, cálice dialissépalo, sépalas 2 externas e 2 laterais, 1-2 mm compr., 2 internas; pétalas $2-3 \mathrm{~mm}$ compr., obovadas, apêndice adnato à base da pétala, cuculado, com crista amarelada no ápice; nectários 4, dorsais ovados, laterais elipsoides; estames 2-2,5 $\mathrm{mm}$ compr., filetes vilosos, pistilódio glanduloso; estaminódios $0,5-1,5 \mathrm{~mm}$ compr., gineceu 1,5-2,5 $\mathrm{mm}$ compr., pubescente, estigma trífido. Cápsula septífraga, 2,5-3,5 × 2,5-3,5 cm, globosa, 3-alada, inflada. Semente $0,5-1 \times 0,5 \mathrm{~cm}$, obovoide.

Material examinado: 25.I.2000, fl. e fr., A. Silva 98920 (IPA).

Material adicional: Recife, Cidade Universitária, 22.X.1972, bt., S. Burgos 57 (UFP).

Espécie cosmopolita, amplamente distribuída nas Américas, África, sul da Ásia e Oceania (Ferrucci 1991). No Brasil ocorre nos estados do Acre, Amazonas, Amapá, Pará, Roraima, Maranhão, Mato Grosso do Sul, Minas Gerais, Rio de Janeiro, São Paulo, Paraná, Rio Grande do Sul e Santa Catarina (BFG 2015). Na USJ está representada por apenas uma coleta e se distingue das demais espécies de trepadeiras por apresentar frutos inflados. Popularmente é conhecida como cipó-de-vaqueiro. 

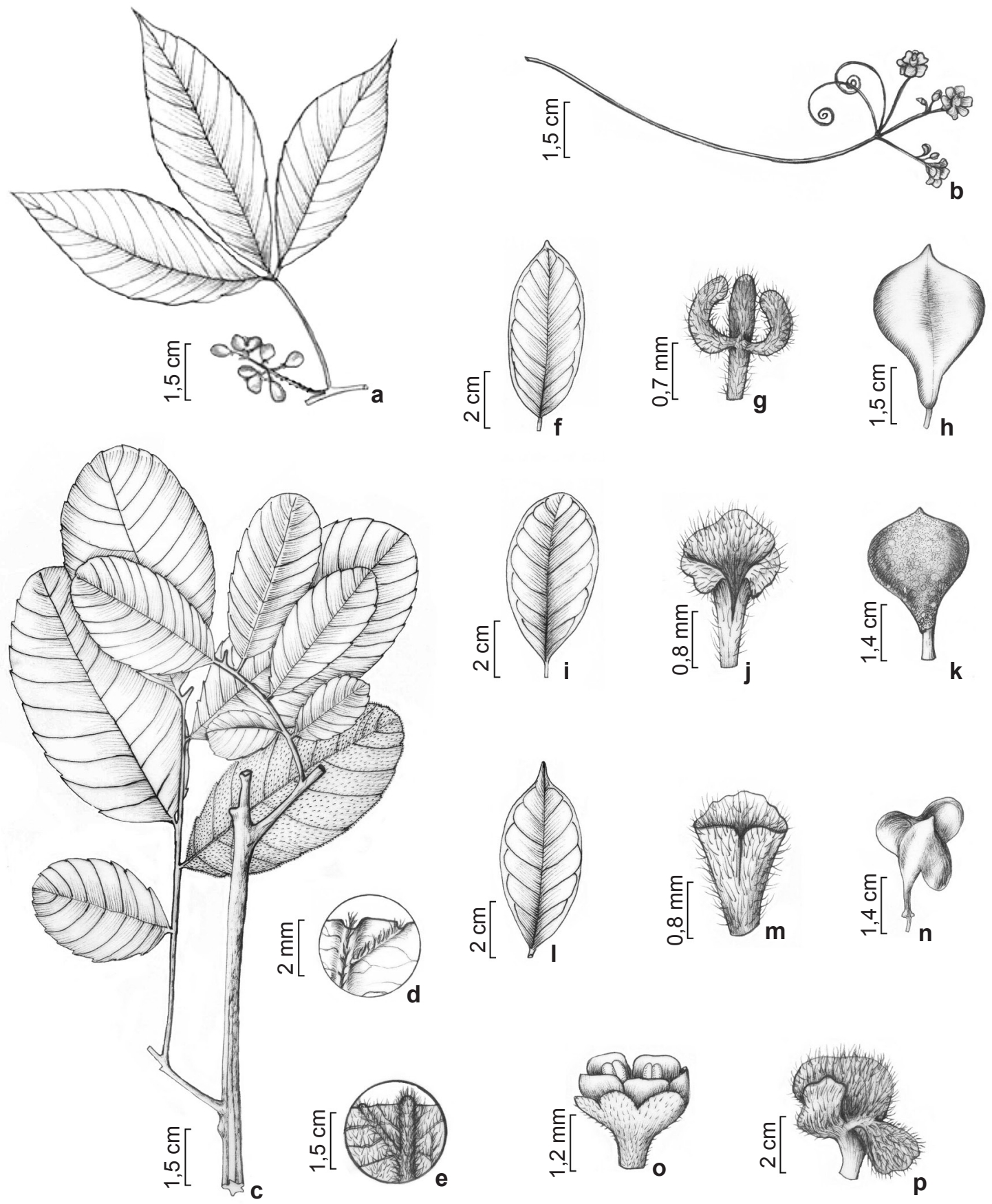

Figura 1 - a. Allophylus laevigatus - ramo frutífero. b. Cardiospermum halicacabum - inflorescência. c-e. Cupania impressinervia - c. ramo estéril; d. detalhe da face adaxial, evidenciando as nervuras impressas; e. detalhe da faca abaxial, evidenciando o indumento. f-h. Cupania ludowigii-f. folíolo; g. pétala; h. fruto. i-k. Cupania oblongifolia-i. folíolo; j. pétala; k. fruto. 1-n. Cupania racemosa - 1. folíolo; m. pétala; n. fruto. o-p. Matayba guianensis - o. flor; p. pétala com apêndices. Figure 1 - a. Allophylus laevigatus - branch with fruits. b. Cardiospermum halicacabum - inflorescence. c-e. Cupania impressinervia - c. sterile branch; d. detail adaxial surface, evidencing printed ribs; e. detail abaxial surface, evidenciang the indumentum. f-h. Cupania ludowigii - f. leaflets; g. petal; h. fruit. i-k. Cupania oblongifolia - i. leaflets; j. petal; k. fruit. 1-n. Cupania racemosa - 1. leaflets; m. petal; n. fruit. o-p. Matayba guianensis - o. flower; p. petal with appendices. 


\section{Cupania L.}

Árvores não-latescentes. Folhas pinadas, raque não alada, apículo terminal presente; pecíolo 3,5-5 cm compr.; folíolos coriáceos; venação broquidódroma. Flores pentâmeras, actinomorfas; cálice dialissépalo; nectário anelar; filete dos estames e pistilódio vilosos. Cápsula loculicida. Semente com excrescência ocupando o 1/3 basal.

Amplamente distribuida nos Neotrópicos sendo 32 espécies registradas para o Brasil, das quais 14 ocorrem na Mata Atlântica nordestina (BFG 2015). Na USJ foram registradas quatro espécies do gênero.

\section{Cupania impressinervia Acev.-Rodr., BioLlania} 6: 147. 1997.

Fig. 1c-e

Árvores até $8 \mathrm{~m}$ alt., ramos floríferos ferrugíneo-tomentosos, 5-sulcados. Folhas 6-11-folioladas; pecíolo 4-5 cm compr.; folíolos 5,5-11 × 3-7 cm, sem domácias, obovados a oblongos; ápice obtuso, arredondado, retuso a emarginado; margem inteira, revoluta, denteadoserreada; base arredondada a aguda, assimétrica; face adaxial glabrescente, nervuras impressas; face abaxial ferrugíneo-tomentosa. Tirso paniculiforme, axilar ou terminal. Flores 4-8 mm compr., sépalas 2-3 mm compr., oblongas, ferrugíneo-tomentosas; pétalas $2-3 \mathrm{~mm}$ compr., unguiculadas, com fenda mediana formando apêndices marginais, vilosos; nectário 5-lobado, glabro; estames 4-5 mm compr., pistilódio 1-1,5 mm compr.; estaminódios 2,5-3 mm compr., gineceu 4-6 mm compr., pubescente. Fruto $1,5-2 \times 2-3 \mathrm{~cm}$, trivalvar, obovoide, ferrugíneo-tomentosa, apiculada, epicarpo viloso. Semente $1-1,3 \times 0,6-0,8 \mathrm{~cm}$, excrescência alaranjada.

Material examinado: Mata de Pezinho, 1.XII.2011, bt., B.S. Amorim et al. 1312 (UFP); Engenho Campinas, 8.X.2007, fl., L.M. Nascimento et al. 633 (UFP); 30.VII.2007, bt., L.M. Nascimento et al. 607 (UFP).

Material adicional: Lagoa dos Gatos, 26.V.2011, fr., E. Ferraz 1098 (IPA).

Espécie endêmica do Brasil, ocorre nos estados de Alagoas, Bahia, Ceará, Paraíba, Pernambuco, Rio Grande do Norte e Sergipe (BFG 2015). Na USJ é ocasionalmente encontrada na borda e interior dos remanescentes. Diferenciase das demais espécies arbóreas pela presença de indumento ferrugíneo-tomentoso nos ramos, flores e frutos. Por muito tempo foi identificada como C. revoluta Radlk., mas Acevedo-Rodríguez (1997) observou que este tratava-se de um nome ilegítimo, propondo uma nova combinação, $C$. impressinervia. $\mathrm{O}$ epíteto faz referência às nervuras da face adaxial dos folíolos que são impressas. Popularmente é conhecida como caboatã-de-rego.

4. Cupania ludowigii Somner \& Ferrucci, Bot. J. Linn. Soc. 146(2): 217-221. $2004 . \quad$ Fig. 1f-h Árvores até $10 \mathrm{~m}$ alt., ramos floríferos pilosos. Folhas 2-5-folioladas; pecíolo 3,5-5 cm compr.; folíolos 6-15 × 3-6,5 cm compr., ovados, elípticos, obovados a oblongos; ápice agudo a obtuso; margem inteira ou levemente revoluta; base cuneada a arredondada; face adaxial com nervuras não-impressas, abaxial glabra, domácias foveoladas nas axilas das nervuras. Tirso paniculiforme, axilar ou terminal, pubescente. Flores 4-5 mm compr., sépalas 1,5-2 mm compr., obovadas a oblongas, pubescentes; pétalas $1-1,5$ $\mathrm{mm}$ compr., unguiculadas, apêndices falciformes inseridos na região mediana, sobrepostos na flor aberta, vilosos; nectário anelar, glabro; estames 2,5-3 mm compr., pistilódio $1 \mathrm{~mm}$ compr.; estaminódios 1,5-2 $\mathrm{mm}$ compr., gineceu 2-3 $\mathrm{mm}$ compr., viloso, lateralmente achatado. Fruto $0,8-1 \times 1-1,3 \mathrm{~cm}$, bivalvar, achatada lateralmente, glabra, apiculada, epicarpo estriado. Semente 1,5$0,8 \times 0,5-0,7 \mathrm{~cm}$ compr., excrescência amarelada. Material examinado: Mata de Piedade, 28.X.2009, fl. e fr., J.A.N. Souza et al. 539 (UFP); Mata de Zambana, 04.IX.2007, fr., A. Alves-Araújo et al. 552 (UFP); 28.VII. 2007, fr., A. Alves-Araújo et al. 463 (UFP).

Espécie endêmica do Brasil, ocorre nos estados de Alagoas, Bahia, Paraíba, Pernambuco, Rio Grande do Norte, Espírito Santo, Minas Gerais, Rio de Janeiro e São Paulo (BFG 2015). Na USJ é uma espécie rara e restrita ao interior dos fragmentos. Diferencia-se das demais espécies arbóreas por apresentar fruto bivalvar, achatado lateralmente. Popularmente é conhecida como caboatã.

5. Cupania oblongifolia Mart., Flora 21(2): 67. 1838.

Fig. 1i-k

Árvores até $7 \mathrm{~m}$ alt., ramos floríferos glabros, lenticelados. Folhas 3-6-folioladas; pecíolo 2,5-6 cm compr.; folíolos 3-11 × 1,5-6 cm, obovados a oblongos; ápice obtuso, emarginado; margem inteira ondulada ou denteado-serreada, levemente revoluta; base cuneada a levemente atenuada; face adaxial com nervuras não-impressas, abaxial glabra, domácias foveoladas nas axilas das nervuras. Tirso racemiforme ou paniculiforme, axilar ou terminal, glabrescente. Flores 4-6 mm compr.; sépalas 2-2,5 mm compr., obovadas, oblongas, pubescentes; pétalas $2-3 \mathrm{~mm}$ compr., obovadas, unguiculadas, com fenda mediana 
formando apêndices marginais, vilosos; nectário anelar, glabro; estames 3-4 mm compr.; pistilódio $1 \mathrm{~mm}$ compr.; estaminódios 2-2,5 mm compr.; gineceu 3,5-4 mm compr., pubescente. Fruto $1-2,5 \times 0,8-2 \mathrm{~cm}$ compr., trivalvar, globosa, epicarpo lenticelado. Semente $0,5-0,7 \times 0,3-0,5$ $\mathrm{cm}$, excrescência alaranjada.

Material examinado: Mata de Macacos, 23.XII.2011, bt., B.S. Amorim et al. 1335 (UFP).

Material adicional: São Vicente Férrer, Mata do Estado, 22.III.1999, fr., E.M.N. Ferraz et al. 631 (PEUFR, UFRN). Jaqueira, RPPN Frei Caneca, 23.IV.2003, fl., J. Leal 32 (UFP).

Espécie endêmica do Brasil, ocorre nos estados do Amapá, Pará, Alagoas, Bahia, Paraíba, Pernambuco, Piauí, Rio Grande do Norte, Espirito Santo, Minas Gerais, Rio de Janeiro, São Paulo, Paraná, Rio Grande do Sul e Santa Catarina (BFG 2015). Na USJ é uma espécie pouco coletada, sendo encontrada no interior dos remanescentes. Diferencia-se das demais espécies arbóreas pela presença de lenticelas esbranquiçadas na superfície dos frutos. Popularmente é conhecida como cabatãde-vassoura.

6. Cupania racemosa (Vell.) Radlk., Sitzungsber. Bayer. Akad. Wiss. München 9: 521. 1879.

Fig. 11-n

Árvores até $8 \mathrm{~m}$ alt., ramos floríferos glabros, lenticelados. Folhas 4-7-folioladas; pecíolo 2-7 cm compr.; folíolos 5-12 × 2,5-5 cm, elípticos a oblongos; ápice agudo a acuminado; margem inteira; base atenuada; face adaxial com nervuras não-impressas, abaxial glabra, domácias foveoladas nas axilas das nervuras. Tirso racemiforme ou paniculiforme, axilar ou terminal, pubescente. Flores 4-6 mm compr.; sépalas $2-2,5 \mathrm{~mm}$ compr., ovadas, pubescentes; pétalas 1,5-2 mm compr., obovadas, com fenda mediana, vilosas; nectário glabro; estames 4-4,5 mm compr.; pistilódio 1,5-2 mm compr.; estaminódios 2-2,5 mm compr.; gineceu 3-3,5 $\mathrm{mm}$ compr., pubescente. Fruto $2-3 \times 2-2,5 \mathrm{~cm}$ compr., trivalvar, trígona, apiculada, com epicarpo estriado. Semente $2-2,8 \times 0,5-0,8 \mathrm{~cm}$ compr., excrescência amarelo-alaranjada.

Material examinado: Mata de Pezinho, 1.XII.2011, fr., B.S. Amorim et al. 1311 (UFP); 4.X.2007, fr., A. AlvesAraújo et al. 590 (UFP); 26.XI.2008, fr., T.L. Costa 23 (UFP); Mata de Piedade, 29.X.2009, fr., J.A.N. Souza et al. 544 (UFP); Mata de Zambana, 17.VII. 2077, fl., A. Alves-Araújo et al. 405 (UFP); 18.X.2007, fr., A. Alves-Araújo et al. 639 (UFP); Mata dos Macacos, 23.XII.2012, fr., B.S. Amorim et al. 1333 (UFP).
Espécie endêmica do Brasil, ocorre nos estados de Alagoas, Bahia, Paraíba, Pernambuco, Rio Grande do Norte, Sergipe, Espírito Santo Minas Gerais e Rio de Janeiro (BFG 2015). Na USJ é frequentemente encontrada na borda dos remanescentes. Diferencia-se das demais espécies arbóreas pelos folíolos glabros com margem inteira e cápsulas trígonas. Popularmente é conhecida como caboatã-preta, caboatã-roliça e caboatãde-birro.

7. Matayba guianensis Aubl., Hist. pl. Guiane 1: 331. 1775.

Fig. 1o-p

Árvores até $6 \mathrm{~m}$ alt., não-latescentes, ramos floríferos pubérulos. Folhas pinadas 6-folioladas, raque não alada, apículo terminal presente; pecíolo 2-5 cm compr.; folíolos 9-16 × 3,5-4,5 cm compr., elípticos, cartáceos; ápice agudo; margem inteira; base atenuada; face adaxial com nervuras nãoimpressas, abaxial glabra, domácias foveoladas nas axilas das nervuras; venação broquidódroma. Tirso racemiforme ou paniculiforme, axilar ou terminal, pubescente. Flores 3,5-5 mm compr., pentâmeras, actinomorfas, cálice curtamente gamossépalo, lacínios do cálice 1-2 mm compr., ovados, pubescentes; pétalas 1-2 mm compr., obovadas, unguiculadas, fenda mediana formando apêndices marginais, densamente vilosas; nectário anelar, glabro; estames 2-3 mm compr., filetes vilosos, pistilódio $1 \mathrm{~mm}$ compr., viloso; estaminódios 1,5 mm compr., gineceu 3-4 mm compr., pubescente. Cápsula loculicida, 1,5-2,5 × 1,2-2 cm, obovada, glabra, epicarpo verrucoso. Semente $1-1,5 \times 0,8$ $\mathrm{cm}$, excrescência alaranjada ocupando o $1 / 3$ basal. Material examinado: Mata de Zambana, 13.III.2009, fr., J.A.N. Souza et al. 406 (UFP).

Material adicional: Goiana, RPPN Fazenda Tabatinga 30.V.2011, fr., D. Cavalcanti et al. 528 (UFP); 16.IV.2011, fl., D. Cavalcanti et al. 497 (UFP); 22.VIII.2010, fr. D. Cavalcanti et al. 244 (UFP).

Espécie amplamente distribuída na América do Sul (Coelho et al. 2012), no Brasil ocorre em todas as regiões do país (BFG 2015). $\mathrm{Na}$ USJ é uma espécie ocasional, encontrada nas bordas dos fragmentos. Diferencia-se das demais espécies arbóreas por apresentar cálice curtamente gamossépalo e epicarpo verrucoso. É conhecida popularmente como cabatã-branco.

\section{Paullinia L.}

Trepadeiras lenhosas. Folhas imparipinadas, apículo terminal ausente. Tirsos com mais de três ramificações. Flores tetrâmeras, zigomorfas, cálice dialissépalo, sépalas 2 externas, 2 internas; 
apêndice adnato à base da pétala, cuculado com crista amarelada no ápice; nectários 4, dorsais ovados; filete dos estames viloso; gineceu pubescente, estigma trífido. Cápsula septífraga com excrescência branca.

Amplamente distribuida na América Central e do Sul sendo 100 espécies registradas para o Brasil, das quais cerca de 1/3 ocorrem na Mata Atlântica e 19 estão citadas para esse domínio fitogeográfico no Nordeste do Brasil (BFG 2015). Na USJ foram registradas três espécies do gênero.

8. Paullinia micrantha Cambess. in A. St.-Hil., A. Juss. \& Cambess., Fl. Bras. merid. 1: 373. 1828.

Fig. 2a-b

Trepadeiras não-latescentes, caule em secção transversal com um cilindro vascular, pubérulo a glabro; estípulas triangulares, caducas. Folhas 9-11-folioladas, raque alada; pecíolo 1-4 cm compr., canaliculado; folíolos 1-5,5 × 1-3 $\mathrm{cm}$, ovados, obovados a elípticos; ápice agudo a arredondado; margem denteada, levemente revoluta; base cuneada a atenuada; face adaxial e abaxial pubérulas a glabras, domácias nas axilas das nervuras secundárias; venação craspedódroma. Tirsos racemiformes, axilares. Flores $4-5 \mathrm{~mm}$ compr., sépalas laterais $0,8-1 \mathrm{~mm}$ compr., 1 dorsal e 1 ventral 1,5-2 mm compr., pubescentes; pétalas 2-3 $\mathrm{mm}$ compr., obovadas,; nectários laterais orbiculares; estames 1-2 mm compr., pistilódio glanduloso; estaminódios $0,5-1,5 \mathrm{~mm}$ compr., gineceu 1,5-2,5 mm compr. Fruto 1,3-1,5 $\times 1-1,2 \mathrm{~cm}, 3$-alada, obovoide. Semente $0,5-1 \times$ $0,5 \mathrm{~cm}$, obovoide, excrescência cobrindo até $2 / 3$ da semente.

Material examinado: Mata de Pezinho, 16.VIII.2007, fr., D. Araújo 442 (UFP); Mata de Piedade, 15.VIII.2009, fr., J.D. García-González 1103 (UFP); 26.I.2010; Mata de Santa Helena, 05.III.2008, fr., A.C.B. Lins-e-Silva 385 (UFP); Mata de Zambana, 22.II.2007, bt., N.A. Albuquerque 217 (UFP, IPA); 19.X.2007, bt., A. AlvesAraújo 659 (UFP).

Segundo BFG (2015), é endêmica do Brasil, ocorrendo nos estados de Alagoas, Bahia, Paraíba, Pernambuco, Rio Grande do Norte, Sergipe, Minas Gerais, Rio de Janeiro e São Paulo. Entretanto, Acevedo-Rodríguez \& Beck (2005) citam sua ocorrência para outros países na América do Sul. $\mathrm{Na}$ USJ é uma espécie ocasional, encontrada predominantemente na borda dos remanescentes. Diferencia-se das demais espécies de trepadeiras pelas folhas imparipinadas 9-11-folioladas e com raque alada. Popularmente é conhecida como cipó-mandioca.
9. Paullinia pinnata L., Sp. pl. 1:366. 1753.

Fig. 2c-d

Trepadeiras lenhosas, caule em secção transversal composto por um cilindro vascular central maior e três periféricos menores, pubérulo a glabro; estípulas triangulares, lineares, persistentes. Folhas 5-folioladas, raque alada; pecíolo $3-8,5 \mathrm{~cm}$ compr., alado; folíolos 6-12,5 ×2-4,5 cm, obovados a elípticos; ápice agudo; margem denteada; base cuneada; face adaxial e abaxial pubérulas a glabras, domácias nas axilas das nervuras secundárias; venação craspedódroma. Tirsos racemiformes, axilares. Flores $4-5 \mathrm{~mm}$ compr., sépalas laterais 0,8-1 mm compr., 1 dorsal e 1 ventral, $1,5-2 \mathrm{~mm}$ compr., pubescentes; pétalas $2-3 \mathrm{~mm}$ compr., obovadas; nectários laterais orbiculares; estames 1-2 mm compr., pistilódio viloso; estaminódios 0,5-1,5 mm compr., gineceu 1,5-2,5 mm compr. Fruto $2-3,5 \times 0,7-1 \mathrm{~cm}$, piriforme, não-alada. Semente $1-1,5 \times 0,5 \mathrm{~cm}$, elipsoide, excrescência cobrindo até $3 / 4$ da semente, formando uma fenda dorsal e outra ventral.

Material examinado: Engenho Campinas, 13.III.2009, fl., L.M. Nascimento \& G. Batista 799 (UFP). Mata de Piedade, 26.III.2008, fl. e fr., A. Melo \& T. Arruda 229 (UFP, IPA); 11.IV.2007, fr., J.S. Marques \& N. Albuquerque 18 (UFP); 26.I.2010, fr., J.D. GarciaGonzález 1390 (UFP).

Espécie amplamente distribuída na América do Sul, sendo a única do gênero com ocorrência na África (Somner 2001). No Brasil ocorre nos estados do Amazonas, Pará, Rondônia, Tocantins, Alagoas, Bahia, Ceará, Maranhão, Paraíba, Pernambuco, Piauí, Rio Grande do Norte, Sergipe, Goiás, Mato Grosso, Mato Grosso do Sul e Paraná (BFG 2015). Na USJ é uma espécie ocasional, encontrada na borda dos remanescentes. Diferencia-se das demais espécies de trepadeiras pelas folhas imparipinadas 5 -folioladas com pecíolo e raque alados. Paullinia elegans é morfologicamente semelhante a $P$. pinnata, apresentando folhas pinadas 5-folioladas, mas pode ser diferenciada desta pela ausência de ala no pecíolo e raque. Popularmente é conhecida como mata-fome.

10. Paullinia racemosa Wawra, Oesterr. Bot. Z. 29: 215.1879.

Fig. 2e-f

Trepadeiras lenhosas, latescentes; caule em secção transversal com um cilindro vascular, glabro; estípulas triangulares, caducas. Folhas 5-folioladas, raque não-alada; pecíolo $1-1,5 \mathrm{~cm}$ compr., sulcado; folíolos 4,5-8 × 2,5-4 cm, ovados, oblongos a elípticos; ápice agudo a acuminado; margem inteira; base cuneada a atenuada; face 

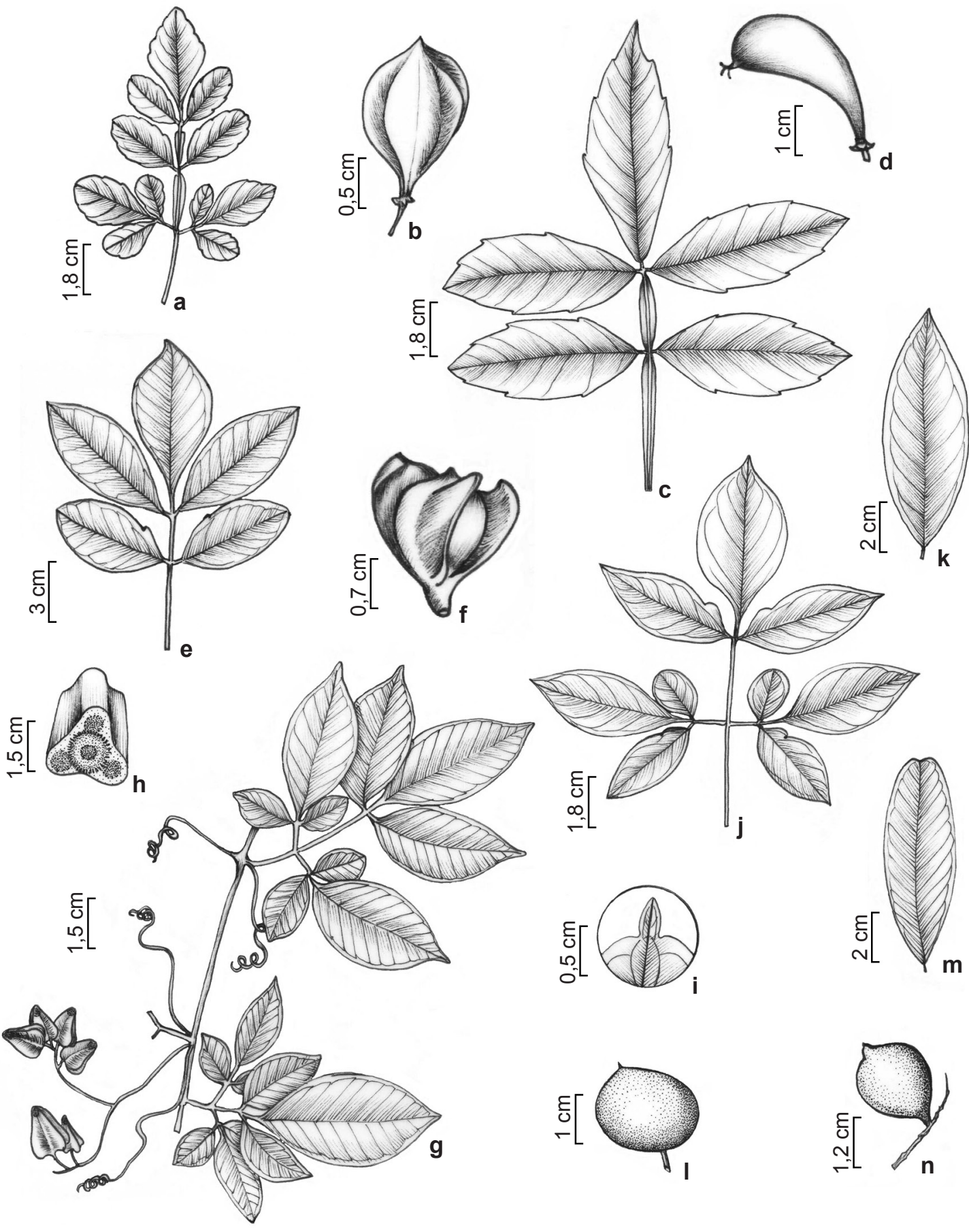

Figura 2 - a-b. Paullinia micrantha - a. folha; b. fruto. c-d. Paullinia pinnata - c. folha; d. fruto. e-f. Paullinia racemosa - e. folha; f. fruto. g-i. Serjania paucidentata - g. hábito; h. detalhe do corte transversal do caule; i. detalhe do ápice linguliforme. j. Serjania salzmanniana - folha. k-1. Talisia esculenta - k. folíolo; 1 . fruto. m-n. Talisia retusa - m. folíolo; $\mathrm{n}$. fruto. Figure 2 - a-b. Paullinia micrantha - a. leaf; b. fruit. c-d. Paullinia pinnata - c. leaf; d. fruit. e-f. Paullinia racemosa - e. leaf; f. fruit. g-i. Serjania paucidentata - g. habit; h. detail cross-section of stem; i. detail linguliformea apex. j. Serjania salzmanniana - leave. k-1. Talisia esculenta - k. leaflet; 1. fruit. m-n. Talisia retusa - m. leaflet; n. fruit. 
adaxial e abaxial glabras, domácias nas axilas das nervuras secundárias; venação broquidódroma. Tirsos racemiformes ou paniculiformes, axilares ou terminais. Flores 4-5 mm compr., sépalas laterais $0,8-1 \mathrm{~mm}$ compr., 1 dorsal e 1 ventral 1,5-2 mm compr., pubescentes; pétalas $2-3 \mathrm{~mm}$ compr., obovadas; nectários laterais orbiculares; estames 1-2 mm compr., pistilódio glanduloso; estaminódios 0,5-1,5 mm compr., gineceu 1,5-2,5 $\mathrm{mm}$ compr., Fruto 1-1,5 × 1,2-1,6 cm, obovoide, 3 -aladas, ala curva quando seca. Semente $0,5-1$ $\times 0,5-0,8 \mathrm{~cm}$, obovoide, excrescência cobrindo $1 / 2-2 / 3$ da semente.

Material examinado: Mata de Macacos, 28.III.2003, fr., A. Melquiades \& G.J. Bezerra 116 (UFP, PUFR); Mata de Piedade, 20.IV.2009, fr., J.D. García 1483 (UFP); 28.VI.2001, fr., H.C.H. Silva 17 (UFP, PEUFR); Mata de Zambana, 22.II.2007, bt., N. Albuquerque 217 (UFP, IPA).

Endêmica do Brasil, ocorre nos estados do Pará, Alagoas, Bahia, Ceará, Maranhão, Paraíba, Pernambuco, Rio Grande do Norte, Espírito Santo, Minas Gerais, Rio de Janeiro e São Paulo (BFG 2015). Na USJ é uma espécie ocasional, encontrada na borda dos remanescentes. Diferencia-se das demais espécies de trepadeiras pela presença de látex. Nos remanescentes de Floresta Atlântica do Sudeste do Brasil, comumente apresenta um par de foliólulos reduzidos nos folíolos basais o que não foi observado nos materiais analisados na USJ. Paullinia elegans, que não ocorre na área de estudo, pode ser morfologicamente associada a $P$. racemosa, mas difere desta pela margem dos folíolos serreada e frutos não-alados. Popularmente é conhecida como cipó mata-fome.

\section{Serjania Mill.}

Trepadeiras lenhosas, não-latescentess. Folhas biternadas 9-folioladas, apículo terminal ausente; pecíolo canaliculado; folíolos sem domácias; glabros, margem inteira; venação broquidódroma. Tirsos racemiformes, axilares, com mais de três ramificações, pubescentes. Flores tetrâmeras, zigomorfas, cálice dialissépalo, sépalas 2 externas, 2 internas; pétalas obovadas, unguiculadas, apêndice adnato à base da pétala, cuculado com crista amarelada no ápice; nectários 4; filete dos estames e ovário vilosos. Fruto esquizocárpico, mericarpos-3, alados.

Amplamente distribuida nos Neotrópicos sendo 119 espécies registradas para o Brasil, das quais cerca de 50 ocorrem na Mata Atlântica nordestina (BFG 2015). Na USJ foram registradas duas espécies do gênero.
11. Serjania paucidentata DC., Prodr. 1: 603. 1824.

Fig. 2g-i

Trepadeiras com caule 6-sulcado, em secção transversal composto por um cilindro vascular central maior e 3 periféricos menores, pubescente a glabro; estípulas ovadas, caducas. Folhas com raque levemente alada; pecíolo $1,5-5 \mathrm{~cm}$ compr.; folíolos 3-11,5 × 2-4 cm, obovados a oblongos; ápice obtuso a acuminado com apículo linguliforme; margem denteada na região apical; base cuneada a atenuada. Flores 5-6 mm compr., sépalas laterais $2,5-3 \mathrm{~mm}$ compr., ovadas a orbiculares, 1 dorsal e 1 ventral 3,5-4 mm compr., obovadas a oblongas, tomentosas; pétalas $4,5-5$ $\mathrm{mm}$ compr., unguiculadas,; nectários orbiculares, semelhantes entre si; estames 2,5-4 mm compr.; pistilódio $1 \mathrm{~mm}$ compr.; estaminódios 1,5-2 cm compr., gineceu 2,5-3 mm compr. Fruto 2,5-3 2-2,8 cm, mericarpos, alados, oblongo-ovados, porção seminífera distal pubescente. Semente esférica.

Material examinado: Mata de Piedade, 3.II.2010, fr., J.D. García 1429 (UFP); 26.I.2010, bt. e fl., J.D. García 1382 (UFP); Mata de Macacos, 19.XII.2007, bt., D. Araújo \& A. Alves-Araújo 499 (UFP, IPA); Mata de Santa Helena, 28.I.2009, bt. e fl., E. Pessoa \& T. Arruda 42 (UFP); Fragmento Chave, 24.XI.2009, bt., E.M. Pessoa \& J.A.N. Souza 161 (UFP).

Ocorre na Bolívia, Venezuela, Nicarágua, Costa Rica, Panamá, Colômbia, Trinidade, Guiana e Guiana Francesa (Acevedo-Rodríguez \& Beck 2005). No Brasil está registrada nos estados do Acre, Ceará e Minas Gerais (BFG 2015). Apesar de não ser citada na Lista do Brasil para o estado de Pernambuco, Oliveira \& Zickel (2002) já haviam registrado sua ocorrência. Na USJ é uma espécie comum, encontrada nas bordas dos fragmentos. Diferencia-se das demais espécies de trepadeiras pelas folhas biternadas, ápice dos folíolos terminais com apículo linguliforme e caules compostos com um cilindro vascular central maior e três periféricos menores. Popularmente é conhecida como cipócururu.

12. Serjania salzmanniana Schltr., Linnaea 18: 46. 1844. Fig. $2 \mathrm{j}$

Trepadeiras com caule 5-lobado, em secção transversal com um cilindro vascular, pubérulo a glabro; estípulas lineares, persistentes. Folhas com raque não-alada; pecíolo $2-6,5 \mathrm{~cm}$ compr.; folíolos 2,5-10 × 2-6 cm, ovados, obovados a orbiculares; ápice agudo, acuminado a obtuso; margem levemente revoluta; base cuneada, atenuada a arredondada. Flores 7-9 mm compr., sépalas 
laterais, 2,5-3 mm compr., ovadas, 1 dorsal e 1 ventral, 3,5-4 mm compr., obovadas, pubescentes; pétalas 4-5 mm compr.; nectários 2 posteriores ovados, maiores, 2 laterais orbiculares, menores; estames 2-3 mm compr.; pistilódio $1 \mathrm{~mm}$ compr.; estaminódios 1,5-2 mm compr., gineceu 3-5 mm compr. Fruto 2,5-5 × 3-4 cm, mericarposalados, ovados, porção seminífera distal glabra. Semente lateralmente achatada.

Material examinado: Mata de Macacos, 15.VIII.2007, fr., D. Araújo 411 (UFP, IPA); Mata de Piedade, 4.II.2010, fr., J.D. Garcia-González 1434 (UFP); 15.VIII.2009, fr., J.D. Garcia-González 1101 (UFP); Mata da Zambana, 22.XII.2007, fl., D. Araújo 554 (UFP, IPA); Mata de Pezinho, 1.XII.2011, fr., B.S. Amorim et al. 1310 (UFP); Mata de Chave, 8.III.2009, bt., fl. e fr., J.D. GarciaGonzález et al. 937 (UFP).

Endêmica do Brasil, ocorre nos estados do Pará, Alagoas, Bahia, Ceará, Maranhão, Paraíba, Pernambuco, Rio Grande do Norte, Sergipe, Goiás, Mato Grosso, Espírito Santo, Minas Gerais e Rio de Janeiro (BFG 2015). Na USJ é a espécie de Sapindaceae mais frequente, sendo encontrada nas bordas dos remanescentes. Diferencia-se das demais espécies de trepadeiras pela presença de caule lenhoso simples 5-lobado. Popularmente é conhecida como cipó-timbó.

\section{Talisia Aubl.}

Árvores não-latescentes. Folhas pinadas, raque não alada, apículo terminal presente; folíolos sem domácias; margem inteira; base cuneada a atenuada, glabros; venação broquidódroma. Flores pentâmeras, actinomorfas, dialissépalas, sépalas ovadas, pubescentes; pétalas elípticas a oblongas, apêndice adnato à porção mediana da pétala, viloso, ápice bífido; nectário anelar, glabro; filete dos estames, pistilódio e gineceu vilosos. Baga glabra. Semente com excrescência da semente carnosa envolvendo toda sua extensão.

Amplamente distribuida nos Neotrópicos sendo 35 espécies registradas para o Brasil, das quais apenas cinco ocorrem na Mata Atlântica nordestina (BFG 2015). Na USJ foram registradas duas espécies do gênero.

13. Talisia esculenta (Cambess.) Radlk., Sitzungsber. Math.-Phys. Cl. Königl. Bayer. Akad. Wiss. München 8: 345. 1878.

Fig. 2k-1

Árvores até 4-8 m alt., ramos floríferos pubérulos, lenticelados. Folhas 6-7-folioladas; pecíolo 1-3 cm compr.; folíolos 7-14 × 2,5-5,5 $\mathrm{cm}$, elípticos; ápice acuminado; base assimétrica, pulvínulo ausente. Tirso racemiforme, axilar ou terminal, pubescente. Flores 5-8 mm compr., sépalas 3-4 mm compr.; pétalas 3-4 mm compr.; nectário glabro; estames 4-6 mm compr.; pistilódio 1-1,5 mm compr.; estaminódios 2-3 mm compr., gineceu 3-5 mm compr. Fruto $1-2 \times 1-2,5 \mathrm{~cm}$, globosa. Semente $0,8-1,2 \times 1-1,5 \mathrm{~cm}$.

Material examinado: Mata de Pezinho, 1.XII.2011, fl., B.S. Amorim 1307 et al. (UFP);

Material adicional: Recife, Parque Ecológico de Dois Irmãos, 25.XI.2000, fr., T. Costa-Lima et al. 55 (HST).

Espécie com distribuição restrita à América do Sul sendo encontrada na Bolívia, Paraguai e Brasil (Acevedo-Rodriguez 2003), neste último ocorre nos estados do Amazonas, Pará, Alagoas, Bahia, Ceará, Maranhão, Paraíba, Pernambuco, Piauí, Rio Grande do Norte, Sergipe, Goiás, Mato Grosso, Minas Gerais e Rio de Janeiro (BFG 2015). $\mathrm{Na}$ USJ é comum na borda dos fragmentos e pode ser diferenciada das demais espécies arbóreas por apresentar folíolos elípticos com ápice acuminado e frutos do tipo baga. Popularmente é conhecida como pitomba.

14. Talisia retusa R.S. Cowan, Brittonia 7: 403. 1952.

Fig. $2 \mathrm{~m}-\mathrm{n}$

Árvores até 5-10 m alt., ramos floríferos glabros. Folhas 6-8-folioladas; pecíolo $5-8 \mathrm{~cm}$ compr., com pulvino; folíolos 9-15 × 3-5,5 $\mathrm{cm}$, elípticos a oblongos; ápice mucronado, retuso ou emarginado; pulvínulo presente. Tirso paniculiforme, axilar ou terminal, pubérulo. Flores 6-8 mm compr., sépalas 2-3 mm compr.; pétalas 3-5 mm compr.; nectário lobado; estames 4,5-6 mm compr., pistilódio 1-1,5 mm compr.; estaminódios 2-3 mm compr., gineceu 3-5 mm compr. Fruto 4-4,5 $\times 2,5-3 \mathrm{~cm}$, elipsoide. Semente $2,5-3 \times 2-2,8 \mathrm{~cm}$.

Material examinado: Mata de Piedade, 21.XI.2008, fl., A. Melo et al.332 (UFP). 29.IV.2009, fr., A. Alves-Araújo et al. 471 (UFP).

Espécie com distribuição restrita à América do Sul, ocorrendo no Suriname, Guiana, Venezuela, Bolívia e Brasil (Acevedo-Rodriguez 2003), onde é encontrada nos estados do Acre, Pará, Rondônia, Alagoas, Maranhão, Paraíba, Pernambuco, Rio Grande do Norte e Mato Grosso (BFG 2015). Na USJ é rara e encontrada no interior dos fragmentos. Diferencia-se das demais espécies arbóreas por apresentar folíolos elípticos a oblongos com ápice mucronado, retuso ou emarginado, além de fruto do tipo baga. Popularmente é conhecida como pitomba-da-mata. 


\section{Agradecimentos}

Agradecemos o apoio financeiro do $\mathrm{CNPq}$, U.S. National Science Foundation (DEB-0946618), Velux Stiftung, Beneficia Foundation, CAPES e FACEPE; aos curadores e técnicos dos herbários visitados; à Regina Carvalho, as ilustrações botânicas; e ao departamento de botânica Universidade Federal Rural do Rio de Janeiro, a acolhida do primeiro autor durante sua estadia no Rio de Janeiro.

\section{Referências}

Acevedo-Rodríguez, P. 1993. Systematic of Serjania (Sapindaceae). Part I: a revision of Serjania sect. Platycoccus. Memoires of The New York Botanical Garden 67: 1-93.

Acevedo-Rodríguez, P. 1997. Novelties in Neotropical Sapindaceae I. BioLlania 6: 143-151.

Acevedo-Rodriguez, P. 2003. Melicocceae (Sapindaceae): Melicoccus and Talisia. Flora Neotropica 87: 1-179.

Acevedo-Rodríguez, P. \& Beck, H.T. 2005. Sapindaceae. In: Steyermark, J.A.; Berry, P.E. \& Holst, B.K. Flora of the Venezuelan Guayana. Vol. 9. Missouri Botanical Garden, St. Louis. Pp. 46-89.

Acevedo-Rodríguez, P.; Van Welzen, P.C.; Adema, F. \& Van Der Ham, R.W.J.M. 2011. Sapindaceae. In: Kubitzki, K. The Families and Genera of Vascular Plants. Vol. 10. Springer-Verlag Berlin Heidelberg. Pp. 357-407.

Alves-Araújo, A. \& Alves, M. 2010. Flora da Usina São José, Igarassu, Pernambuco: Sapotaceae. Rodriguésia 61: 303-318.

Araújo, D. \& Alves, M. 2010. Climbing plants of a fragmented area of lowland Atlantic forest, Igarassu, Pernambuco (northeastern Brazil). Phytotaxa 8: 1-24.

Aschoff, L. 2012. Variação sazonal e longitudinal na ecologia do Guariba-de-Mãos-Ruivas, Alouatta belzebul (Primates, Atelidae), na Fazenda Pacatuba, Paraíba. Dissertação de Mestrado. Universidade Federal de Sergipe, São Cristóvão. 85p.

BFG. 2015. Growing knowledge: an overview of Seed Plant diversity in Brazil. Rodriguésia 66: 1085-1113.

Buril, M.T. \& Alves, M. 2011. Flora da Usina São José, Igarassu, Pernambuco: Convolvulaceae. Rodriguésia 62: 93-105.

Coelho, R.L.G.; Souza, V.C. \& Ferrucci, M.S. 2012. Matayba obovata, a new species of Matayba sect. Matayba (Sapindaceae) from Brazil. Brittonia 64: 43-48.

Coelho, R.L.G. 2014. Estudos sistemáticos das espécies neotropicais de Allophylus L. (Sapindaceae). Tese de Doutorado. Universidade Estadual de Campinas, Campinas. 449p.

Ferrucci, M.S. 1991. Sapindaceae. In: Spichiger, R. \& Ramella, L. Flora del Paraguay. Vol. 18. Missouri Botanical Garden, St. Louis. Pp. 5-147.
Ferrucci, M.S. 2000. Revision taxonómica de los géneros Cardiospermum y Urvillea para el Neotropico (Sapindaceae). Tese de Doutorado. Universidade Nacional de Córdoba, Córdoba. 262p.

Font Quer, P. 1953. Dicionario de Botanica. Ed. Labor, Barcelona. 1244 p.

Gomes-Costa, G. \& Alves, M. 2012. Flora da Usina São José, Igarassu, Pernambuco: Cucurbitaceae. Rodriguésia 63: 817-829.

Guarim-Neto, G.; Santana, S.R. \& Silva, J.V. 2000. Notas etnobotânicas de Sapindaceae Jussieu. Acta Botanica Brasilica 14: 327-334.

Harris, J.G. \& Harris, M.W. 2001. Plant identification terminology: an illustrated glossary. $2^{\text {nd }}$ ed. Spring Lake Publishing, Utah. 216p.

Hora, R.C. \& Soares, J.J. 2002. Estrutura fitossociológica da comunidade de lianas em uma floresta estacional semidecidual da Fazenda Canchin, São Carlos, SP. Revista Brasileira de Botânica 25: 323-329.

Melo, A.; Amorim, B.S.; García-González, J.; Souza, J.A.N.; Pessoa, E.M.; Mendonça, E.; Chagas, M.; Alves-Araújo, A. \& Alves, M. 2011. Updated floristic inventory of the angiosperms of the Usina São José, Igarassu, Pernambuco, Brazil. Revista Nordestina de Biologia 20: 3-26.

Mori, S.A.; Mattos-Silva, L.A.; Lisboa, G. \& Coradin, L. 1985. Manual de manejo do herbário fanerogâmico. Centro de Pesquisas do Cacau, Ilhéus. Pp. 1-97.

Oliveira, M.A. 1998. A família Sapindaceae Juss. nos brejos de altitude de Pernambuco. Monografia de Graduação. Universidade Federal Rural de Pernambuco, Recife. 60p.

Oliveira, M.A. \& Zickel, C.S. 2002.A família Sapindaceae: taxonomia e distribuição no estado de Pernambuco. In: Tabarelli, M. \& Silva, J.M.C. Diagnóstico da Biodiversidade de Pernambuco. Vol. 2. Secretaria de Ciência, Tecnologia e Meio Ambiente. Editora Massangana, Recife. Pp. 267-279.

Perdiz, R.O. 2011. Sapindaceae em três remanescentes de florestas montanas no sul da Bahia, Brasil. Dissertação de Mestrado. Universidade Estadual de Feira de Santana, Feira de Santana. 129p.

Pereira, L.A. 2014. A família Sapinaceae na Floresta Atlântica do nordeste oriental. Dissertação de Mestrado. Universidade Federal de Pernambuco, Recife. 126p.

Radford, A.E.; Dickison, W.C.; Massey, J.R. \& Bell, C.R. 1974. Vascular Plant Systematics. Harper \& Row, New York. 891p.

Radlkofer, L. 1892-1900. Sapindaceae. In: Martius, C.F.P.; Eichler, A.G. \& Urban, I. (ed.). Flora brasiliensis. Lipsiae, Frid. Fleischer. Vol. 13, pars 3, pp. 226-656.

Reitz, R. 1980. Sapindáceas. In: Reitz, R. Flora ilustrada catarinense. Herbário Barbosa Rodrigues, Itajaí. $156 \mathrm{p}$.

Silva, A.G.; Sá-e-Silva, I.M.M.; Rodal, M.J.N. \& Lins-e-Silva, A.C.B. 2008. Influence of edge and 
topography on canopy and sub-canopy structure of an Atlantic forest fragment in Igarassu, Pernambuco state, Brazil. Bioremediation, Biodiversity and Bioavailability 2: 41-46.

Somner, G.V. 2001. Paullinia L. (Sapindaceae): morfologia, taxonomia e revisão de Paullinia sect. Phygoptilon. Tese de Doutorado. Universidade de São Paulo, São Paulo. 275p.

Somner, G.V.; Ferrucci, M.S.; Rosa, M.M.T. \& Coelho, R.G.L. 2009. Sapindaceae. In: Martins, S.E.; Wanderley, M.G.L.; Shepherd, G.J.; Giulietti, A.M. \& Melhem, T.S. Flora Fanerogâmica do Estado de São Paulo. Instituto de Botânica, São Paulo. Vol. 6, pp. 195-255.
Tamaio, N. \& Angyalossy, V. 2009. Variação cambial em Serjania caracasana (Sapindaceae): Enfoque na adequação terminológica. Rodriguésia 60: 651-666.

Thiers, B. [continuously updated]. Index Herbariorum: a global directory of public herbaria and associated staff. New York Botanical Garden's Virtual Herbarium. Disponível em $<$ http://sweetgum.nybg. org/ih>. Acesso em 7 outubro 2015.

Trindade, M.B.; Lins-e-Silva, A.C.B.; Silva, H.P.; Figueira, S.B. \& Schessl, M. 2008. Fragmentation of the Atlantic rainforest in the Northern coastal region in Pernambuco, Brazil: recent changes and implications for conservation. Bioremediation, Biodiversity and Bioavailability 2: 5-13.

\section{Lista de exsicatas}

Albuquerque, N.A. 217 (10), 317 (8). Alves-Araújo, A. 405 (6), 463 (4), 471 (14), 503 (1), 552 (4), 590 (6), 639 (6), 659 (8), 804 (1), 886 (10). Amorim, B.S. 1132 (3), 1307 (13), 1308 (1), 1310 (12), 1311 (6), 1312 (3), 1331 (1), 1333 (6), 1335 (5). Araújo, D. 411 (12), 442 (8), 499 (11), 554 (12), 588 (11). Burgos, S. 57 (2). Costa, T.L. 4 (6), 23 (6). Ferraz, E. 1098 (3). García-González, J.D. 937 (12), 1101 (12), 1103 (8), 1343 (11), 1382 (11), 1387 (8), 1390 (9), 1429 (11), 1434 (12), 1483 (10). Guerra, T.N.F. 88 (1). Leal, J. 32 (5). Lins-e-Silva, A.B.C. 321 (6), 346 (6), 358 (8). Marques, J.S. 18 (9). Melo, A. 229 (9), 332 (14). Melquíades, A. 116 (10). Mendonça, E.D. 37 (12). Nascimento, L.M. 607 (3), 633 (3), 651 (1), 763 (1), 799 (9). Pessoa, E. 42 (11). Pessoa, E.M. 161 (11). Silva, A. s/n (2). Silva, H.C.H. 17 (10). Souza, J.A.N. 406 (7), 539 (4), 544 (6). 